\title{
Enhancement of grain number per spike by RNA interference of cytokinin oxidase 2 gene in bread wheat
}

Yulian $\mathrm{Li}^{1 \dagger}$, Guoqi Song ${ }^{1 \dagger}$, Jie Gao ${ }^{1}$, Shujuan Zhang ${ }^{1}$, Rongzhi Zhang ${ }^{1}$, Wei $\mathrm{Li}^{1}$, Mingli Chen ${ }^{1}$, Min Liu', Xianchun $\mathrm{Xia}^{3}$, Thierry Risacher ${ }^{2^{*}}$ and Genying $\mathrm{Li}^{\mathrm{i}^{*}}$

\begin{abstract}
Background: This study aimed to validate the function of CKX gene on grain numbers in wheat.

Methods: we constructed and transformed a RNA interference expression vector of TaCKX2.4 in bread wheat line NB1. Southern blotting analysis was used to select transgenic plants with single copy. The expression of TaCKX2.4 gene was estimated by Quantitative real-time PCR (qRT-PCR) analysis. Finally, the relation between expression of TaCKX2.4 gene and grain numbers was validated.

Results: Totally, 20 positive independent events were obtained. Homozygous lines from 5 events with a single copy of transformed gene each were selected to evaluate the expression of TaCKX2.4 and grain numbers per spike in $T_{3}$ generation. Compared with the control NB1, the average grain numbers per spike significantly increased by $12.6 \%, 8.3 \%, 6.5 \%$ and $5.8 \%$ in the $T_{3}$ lines JW39-3A, JW1-2B, JW1-1A and JW5-1A, respectively.
\end{abstract}

Conclusion: Our study indicated that the expression level of TaCKX2.4 was negatively correlated with the grain number per spike, indicating that the reduced expression of TaCKX2.4 increased grain numbers per spike in wheat.

Keywords: CKX2.4, Grain number per spike, Transgenic plant, Triticum aestivum

\section{Background}

The plant hormone cytokinin (CK) promotes cell proliferation and differentiation, and regulates plant growth and development from many processes, such as senescence, shoot and root balance, transduction of nutritional signals, leaf senescence, chloroplast formation and crop productivity [1-3]. CK in grains during the early stage of grain development play an important role in regulating grain filling pattern and consequently influence grain filling percentage [4], and CK in the grains may mediate cell division in rice endosperm at early grain filling stages [5]. CK are the most potent general coordinator between the stay-green trait and senescence.

\footnotetext{
*Correspondence: thierry.risacher@biogemma.com; lgy111@126.com

${ }^{\dagger}$ Yulian Li and Guoqi Song contributed equally to this work.

${ }^{2}$ Biogemma, Site de la Garenne, CS 90126, 63720 Chappes, France

${ }^{1}$ Crop Research Institute, Shandong Academy of Agricultural Sciences; Key Laboratory of Wheat Biology and Genetic Improvement on North Yellow and Huai River Valley, Ministry of Agriculture, National Engineering Laboratory for Wheat and Maize, Jinan 250100, Shandong, China

Full list of author information is available at the end of the article
}

Stay-green can not only increase the yield of wheat but also its resistance to heat stress during active photosynthesis [6]. Exogenous cytokinins can sustain longer active photosynthetic period during the grain filling stage, transfer more assimilates to the grain [7], and increase grain yield under heat stress [6]. The increase of photosynthetic productivity can lead to high yields through improvement of leaf anatomical and biochemical traits including tolerance to non-optimal temperature conditions [8].

Cytokinin oxidases/dehydrogenases (CKX) are important in controlling local cytokinin levels and contribute to the regulation of cytokinin-dependent processes [9]. CKX is regarded as a negative regulator of cytokinin [10]. Overexpression of $C K X$ gene led to reduced endogenous cytokinin contents in plants [11].

A number of $C K X$ genes were cloned from Zea mays [12], Arabidopsis [13], orchid [14], rice [15], barley and wheat [16-20]. The functions of CKX genes were demonstrated in some plants by transgenic technology. The relationship between CKX and CK has been extensively

(C) The Author(s). 2018 Open Access This article is distributed under the terms of the Creative Commons Attribution 4.0 International License (http://creativecommons.org/licenses/by/4.0/), which permits unrestricted use, distribution, and 
investigated to understand their functions in plant development. The CKX activity may be induced by the levels of CK [20]. In Arabidopsis, the transgenic plants with an overexpression of $A t C K X 1$ and $A t C K X 3$ had fewer flowers on each inflorescence stem, indicating a reduction in the ability of apical inflorescence meristems to form new flower primordia [13]. In rice, the transgenic plants with low expression level of OsCKX2 had an increased grain numbers, whereas the transgenic plants with a higher expression level of OsCKX2 showed a lower grain numbers. In addition, an OsCKX2 null variety had high grain yield [15]. This suggested that the different transcript levels of OsCKX2 were responsible for the phenotypic differences of these rice varieties [15]. Down-regulation of OsCKX2 expression increased tiller numbers and improved grain weight [21]. Overexpression or suppression of GhCKX (Gossypium hirsutum L.) in transgenic tobacco led to deficiency of cytokinin (e.g., fewer or no flowers) or over-production of cytokinin (e.g., more flowers and capsules) [19]. In addition, silencing of $H \nu C K X 1$ in transgenic barley resulted in a lower CKX activity and a higher grain yield [17]. So far, there have been no reports of transgenic wheat to prove the function of TaCKX gene.

Wheat is one of the most important staple crops worldwide. To study the relationship between the expression level of CKX and wheat productivity, Zhang et al. [19] cloned TaCKX6 and observed that its haplotype variants were significantly associated with the 1000 -grain weight based on linkage mapping, association study and gene expression analysis. The expression level of two TaCKX2 genes was significantly correlated with grain numbers per spike [18]. However, the relationship between the $C K X$ gene expression and number of reproductive organs in transgenic plants remains unknown. In the present study, a TaCKX2.4 [22] RNA interference vector (piCKX2.4) was constructed and transformed into immature embryos using the seed inoculation method to validate the function of TaCKX2.4 and the relationship between $T a C K X 2.4$ and grain numbers in bread wheat.

\section{Materials and methods}

\section{Plant material and preparation of explants}

Stock plants of NB1 were produced in $17 \mathrm{~cm}$ diameter pots, four plants per pot. Plants are grown in KLASMANN compost, a thin layer of medium vermiculite is scattered on top of the compost. Aquamat was used under the pots to keep the moisture. Place pots in a greenhouse at $25{ }^{\circ} \mathrm{C}$ day/ $20{ }^{\circ} \mathrm{C}$ night with $16 \mathrm{~h}$ photoperiod, $500 \mu \mathrm{E} / \mathrm{m} 2$ /s.

\section{Construction of RNAi interference vector}

In order to use hairpin construct to generate a higher efficiency of RNA silencing, we selected the conserved domain of TaCKX2.4 (located on chromosome 3A) as the RNAi target sequence. The conserved fragment of 1-495 bp of TaCKX2.4 (JN381555.1) was used to design RNAi hairpin structure. The conserved hairpin was inserted into pBIOS2043 under the regulation of the promoter OsActin 1 and Act 1 intron 1 [23] to construct the plant expression RNAi vector pBIOS2043-TaCKX2.4 (Fig.1).

\section{Bacterial strains and culture conditions}

Agrobacterium tumefaciens strain EHA105 was used for gene transformation. Agrobacterium cells were cultured on YEP plate with appropriate antibiotic (Kanamycin, $50 \mathrm{mg} / \mathrm{L}$ ) at $28{ }^{\circ} \mathrm{C}$ for $1 \mathrm{~d}$. Then the bacteria was collected, and re-suspended in $3 \mathrm{ml}$ TSIM medium (MS medium $4.41 \mathrm{~g} / \mathrm{l}$, Myo-inositol $100 \mathrm{mg} / \mathrm{l}$, MES $50 \mathrm{mg} / \mathrm{l}$, Glucose $10 \mathrm{~g} / \mathrm{l}$ ) with $200 \mu \mathrm{M}$ Acetosyringone (AS), and the bacterial suspension was transferred into a small universal tube.

\section{Plant transformation}

Wheat immature embryos transformation was performed as described in Risacher et al. [24]. one microlitre bacterial suspension was injected into each immature seed on the spike using a syringe. The injection should be done between the endosperm and the scutellum. After all ears were inoculated, fix a support cane outside the cylinder and cover with a translucent plastic bag sealed at the base. After $2 \mathrm{~d}$ co-cultivation at $22{ }^{\circ} \mathrm{C}$, isolate the inoculated seeds and extract the embryos by tweezers and blade, and plate the embryos on W4 rest medium (containing MS medium, $100 \mathrm{mg} / \mathrm{l}$ Myo-inositol, $50 \mathrm{mg} / \mathrm{l}$ MES and $10 \mathrm{~g} / \mathrm{l}$ glucose) at $28.5{ }^{\circ} \mathrm{C} / 23{ }^{\circ} \mathrm{C}(16 \mathrm{~h} / 8 \mathrm{~h})$ for $5 \mathrm{~d}$. In $12 \mathrm{~d}$ after isolation, the calli were transferred to the selection medium (W4 added $2.5 \mathrm{ml} / \mathrm{l}$ geneticin) at $25.5{ }^{\circ} \mathrm{C} / 23{ }^{\circ} \mathrm{C}$ $(16 \mathrm{~h} / 8 \mathrm{~h})$, and 2 weeks later, the calli were cut into pieces and transferred to fresh selection medium. After 2 weeks, the calli were transferred to regeneration medium. Regenerated shoots were separated from the calli and transferred onto rooting medium containing MS salts $(20 \mathrm{~g} / \mathrm{l}$ sucrose, $6 \mathrm{~g} / \mathrm{l}$ agarose, $2.5 \mathrm{ml} / \mathrm{l}$ Geneticin and $2 \mathrm{ml} / \mathrm{l}$ Kinetin) [24]. Rooted shoots were transplanted into soil and cultured in the greenhouse. The media for calli of controls didn't have geneticin.

\section{Preliminary screening of homozygous transgenic plants with single copy}

Thirty $T_{1}$ generation seeds harvested from each $T_{0}$ transgenic plant were selected randomly and put into $10 \mathrm{ml}$ tubes. Two times volumes of $2 \mathrm{~g} / \mathrm{l}$ Kanamycin solution were added into the tubes. After being treated at room temperature for $24 \mathrm{~h}$, the seeds were put on the vermiculite to grow at $25{ }^{\circ} \mathrm{C}$. The normal plants from the lines with the ratio of 3 normal to 1 albino plants were selected and transferred them to the soil, grew in 


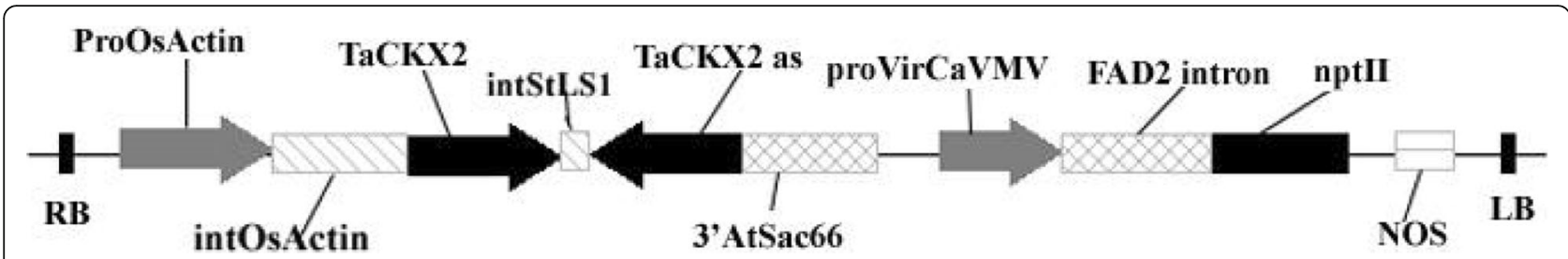

Fig. 1 T-DNA region of the plasmid pBIOS2043-TaCKX2

the greenhouse with controlled environment at $25{ }^{\circ} \mathrm{C} /$ $20{ }^{\circ} \mathrm{C}(16 \mathrm{~h} / 8 \mathrm{~h})$. The seeds of $\mathrm{T}_{2}$ generations were harvested in each individual plant. The $T_{2}$ generation seeds were treated by Kanamycin according to the method mentioned above [24]. The lines with all normal plants, derived from each $T_{1}$ plant, should have a single copy. The transgenic lines with a single copy were verified by Southern blotting analysis.

\section{Molecular analysis of transformed plants $P C R$ analysis}

Transgenic plants were selected by Polymerase Chain Reaction (PCR). Genomic DNA was extracted from young leaf tissues of receptor NB1 and transgenic plants using plant genomic DNA Extraction Kit (Tiangen Biotech, Beijing, China). The gene-specific primers (5'-ATTCTTATTTCTTTCCAGTAGC and 5'-AGAA GCGGCATAATGTGAGA) were used to amplify an 882-bp fragment of FAD2 intron, a fragment of the interference vector. PCR was performed in a total volume of $20 \mu \mathrm{l}$ containing $50 \mathrm{ng}$ of genomic DNA, $2 \mu \mathrm{l}$ PCR buffer, $0.2 \mathrm{mM}$ of forward and reverse primers, and $1.5 \mathrm{U}$ of $\mathrm{Taq}$ polymerase using a PCR Reaction Kit (Tiangen Biotech, Beijing, China). The PCR reaction included DNA denaturation at $94{ }^{\circ} \mathrm{C}$ for $5 \mathrm{~min}$, followed by 38 cycles of denaturation at $94{ }^{\circ} \mathrm{C}$ for $30 \mathrm{~s}$, annealing at $55{ }^{\circ} \mathrm{C}$ for $30 \mathrm{~s}$, and extension at $72{ }^{\circ} \mathrm{C}$ for $30 \mathrm{~s}$, and a final extension at $72{ }^{\circ} \mathrm{C}$ for $10 \mathrm{~min}$. Only the positive transgenic plants can be amplified the expected size, because the FAD2 was the fragment of the vector. In order to confirm the band, we sequenced the amplified product.

\section{Southern blotting analysis}

Genomic DNA was extracted from leaves of T3 transgenic plants with single copies selected preliminarily by Kana and non-transgenic plants using plant genomic DNA Extraction Kit (Tiangen Biotech, Beijing, China). About $20 \mu \mathrm{g}$ of DNA was successfully digested with $5 \mathrm{U}$ of EcoRV and incubated at $37{ }^{\circ} \mathrm{C}$ for $24 \mathrm{~h}$. The digested genomic DNA fragments were separated on a $0.8 \%(w / v)$ agarose gel, and transferred onto Zeta-Probe GT nylon membrane (Bio-Rad, Hercules, CA, USA). The DNA fragments were fixed to the membrane by UV cross linking. The 882-bp PCR fragment of FAD2 intron was labeled with digoxin. The probe labeling, hybridization, washing and detection procedures were performed according to instructions of the DIG High prime DNA labeling and Detection Starter KitII (Roche, Mannheim, Germany).

\section{Quantitative real-time PCR ( $q R T-P C R$ ) analysis}

RNA was extracted from leaves of transgenic plants and the control NB1 using TRIZOL Reagent (Invitrogen, CA, USA) and reverse transcription of RNA was performed using M-MLV RTase Synthesis Kit (Takara, Japan). Quantitative real-time PCR (qRT-PCR) was performed using the Rotor-Gene 3000 Series real time DNA amplification system under the following conditions: $95{ }^{\circ} \mathrm{C}$ for $10 \mathrm{~min} ; 40$ cycles of $95{ }^{\circ} \mathrm{C}$ for $10 \mathrm{~s}, 60{ }^{\circ} \mathrm{C}$ for $20 \mathrm{~s}$ and $72{ }^{\circ} \mathrm{C}$ for $20 \mathrm{~s}$. Melting curve analysis was performed at $95{ }^{\circ} \mathrm{C}$ for $15 \mathrm{~s}, 60{ }^{\circ} \mathrm{C}$ for $1 \mathrm{~min}$, and $97{ }^{\circ} \mathrm{C}$, continuous, using the TaCKX2.4-specific primers (5'-TGTCGGTCGAAGGCCAGTA and 5'-TAGT CGGTCCACGA ACGC). Melting curve analysis was included to verify the specificity of DNA amplification. Expression of the reference gene tubulin, served as quantifying control, was monitored using gene-specific forward and reverse primers (5'-AACTTCGCCCGTGGTCAT and 5'-CAGCGTTGAATACAAGGAATC) under the same condition as that of TaCKX2.4. Three biological replicates were performed for each line and three technical replicates were analyzed for each biological replicate.

\section{Agronomic traits of $T_{3}$ transgenic plants}

Five single-copy transgenic lines and the control NB1 were grown in the isolated field for genetically modified organism (GMO) in Shandong Academy of Agricultural Sciences, Shandong, China. Field trials were conducted in completely randomized blocks with three replicates. Each plot consisted of four 4-m rows with $30 \mathrm{~cm}$ between rows and $20 \mathrm{~cm}$ between plants. The data for spike length (SL), spikelet number per spike (SPN) and grain number per spike (GN) were measured from the main spikes of ten randomly selected plants each plot. SL was the length from the neck node to the top of the spike (did not include the length of awn). Thousand-grain weight (TGW) was measured as the average weight of two independent samples of 1000 grains. The kernel length and kernel width were recorded for 20 randomly selected kernels from each line in triplicate, and the average value was used for subsequent analysis [25]. 


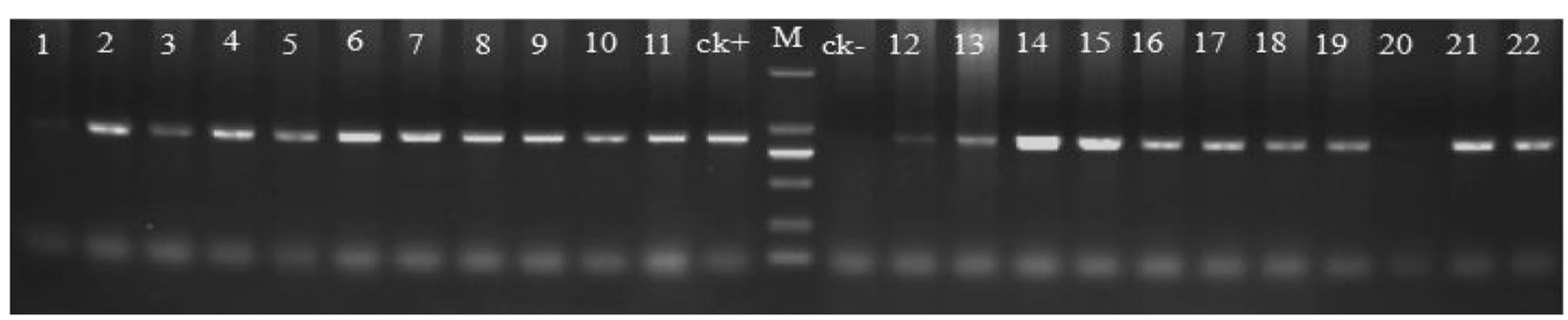

Fig. 2 PCR detection of 22 putative transgenic plants. $1 \sim 22$ are putative transgenic plants, positive control (plasmid DNA as template, CK+) and negative control (non-transgenic plants, CK-)

\section{Results}

\section{Wheat transformation and PCR analysis}

The TaCKX2.4 RNA interference vector (PiCKX2.4) was transformed into immature embryos of wheat line 'NB1' by Agrobacterium. There were 22 putative transgenic plants from 22 independent transgenic lines. In order to avoid the interference of endogenous genes in wheat, the presence of PiCKX2.4 vector in the putative transgenic plants was determined by genomic DNA PCR with the primers specific to FAD2 intron, a fragment of the interference vector. Twenty of 22 primary transformants that could amplify an 882-bp targeting band were PCR-positive (Fig.2), whereas the negative control had no amplified fragments.

Southern analysis of $\mathrm{T}_{0}$ transgenic wheat and homozygous transgenic plants with single copy

Based on the preliminary results of PCR analysis, representative $T_{0}$ transgenic lines were selected for gene integration analysis. Southern blotting analysis indicated that the FAD2 intron on the T-DNA were integrated into the wheat genome at single copies in the JW41-1B, JW1-2B, JW1-1A, JW5-1A and JW39-3A transgenic lines (Fig. 3).

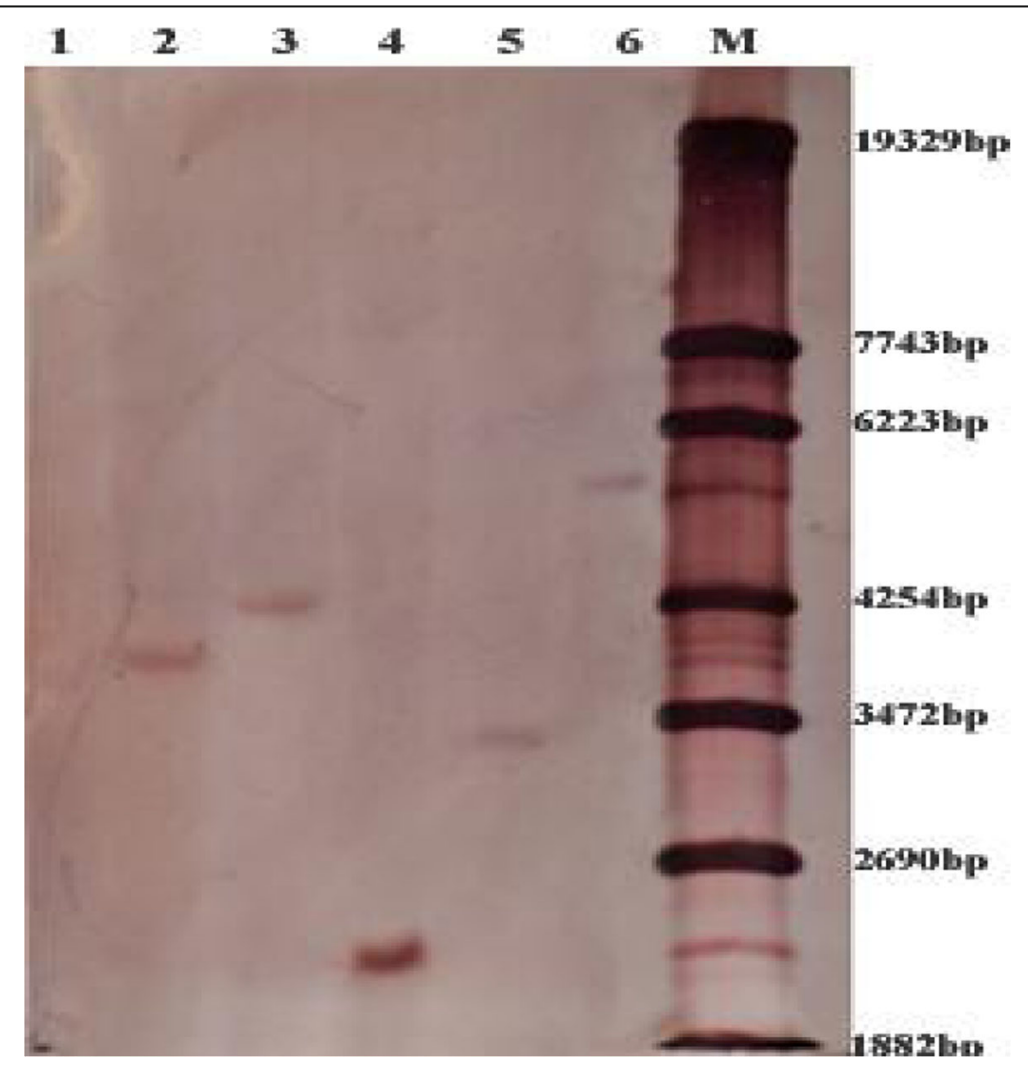

Fig. 3 Southern blotting analysis in selected To primary wheat transformants. Genomic DNA digested with EcoR V and hybridized with FAD2 probe. The number of reactive bands in each lane represents the transgene copies in each transgenic line. Lane 1 is WT (NB1), lanes $2 \sim 6$ are JW1-1A, JW5-1A, JW41-1B, JW39-3A and JW1-2B, respectively, M is the marker: $\lambda$-EcoT14 I digest (TaKaRa, Dalian, China) 


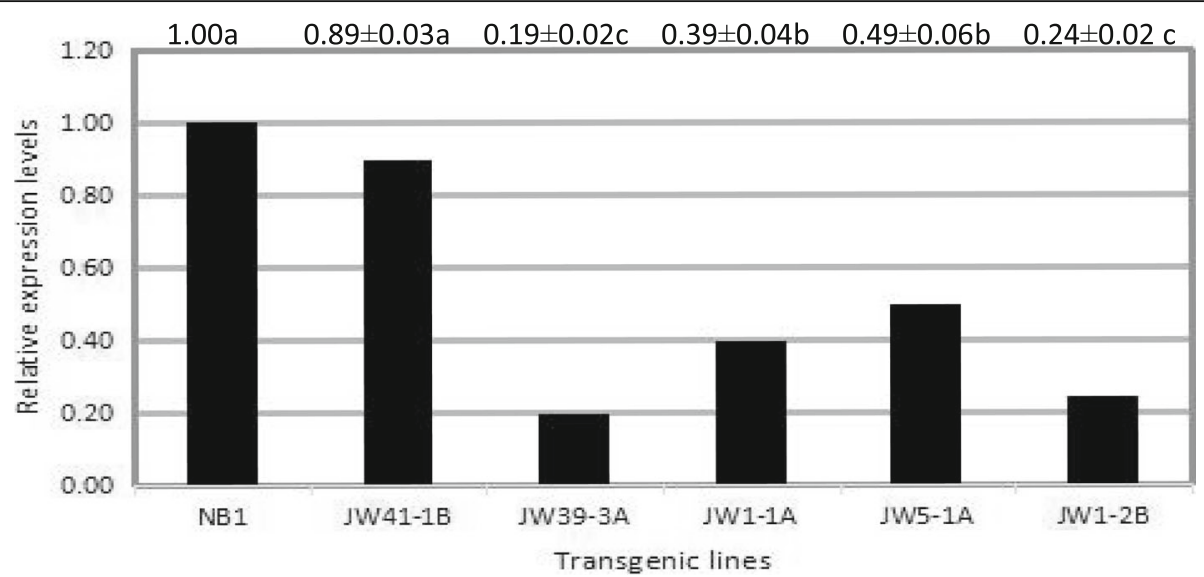

Fig. 4 Relative expression of TaCKX2 in wild type (NB1) and selected $T_{3}$ transgenic lines by qRT-PCR. Total RNA was isolated from young leaves of $\mathrm{NB} 1$ and selected $T_{3}$ transgenic lines. Different lowercase letters following the values indicate significant differences $(P<0.05)$

In order to obtain homozygous transgenic plants with a single copy, 30 seeds from per $\mathrm{T}_{0}$ transgenic plant with a single copy were treated by $2 \mathrm{~g} / \mathrm{L}$ Kana solution. The results showed that five lines had a 3:1 segregation of normal to albino plants, confirming that the five $\mathrm{T}_{0}$ transgenic plants were with single copy. Thirty seeds from per $T_{1}$ normal line were treated by $2 \mathrm{~g} / \mathrm{L}$ Kanamycin solution. Five lines with no segregation were homozygous and selected for subsequent analysis. PCR for $T_{1}$ to $T_{3}$ transgenic lines showed that PiCKX2.4 was stably inherited.

TaCKX2.4 expression in transgenic wheat with single copy The expression of $T a C K X 2.4$ in leaves of $\mathrm{T}_{3}$ lines from selected primary transformants with single copy was analyzed by qRT-PCR using specific primers. There was variation in the expression level of TaCKX2.4 among the five selected transformants. In general, the TaCKX2.4 transcript levels were much lower in the transformants than in controls (Fig. 4). Among them, the lines JW39-3A and JW1-2B had the lowest expression of $\operatorname{TaCKX} 2.4,0.19$ and 0.24 , respectively, relative to the control. Only the line JW41-1B had no significantly different expression from that of the control, which could be attributed to the low expression of shRNA-CKX2.4 in this transgenic line. Overall, the shRNA-CKX2.4 introduced into the wheat genome resulted in reduced expression of TaCKX2.4 in these transgenic lines.

\section{The relationship between $\operatorname{TaCKX2.4}$ expression and wheat agronomic traits}

The $\mathrm{T}_{3}$ homozygous seeds with single copy were grown in the field for phenotype observation. The field trials showed no significant differences in spike length, number of spikelet per spike, kernel length, kernel width and TGW between transgenic and control plants. However, the grain numbers per spike from main tiller of transgenic plants were significantly $(P<0.05)$ increased by $5.8-12.6 \%$ on average compared with those of non-transformed plants (Table 1 and Fig. 5).

To evaluate the relationship between the expression level of TaCKX2.4 gene and grain numbers per spike. qRT-PCR with RNA from the young spikes of five transgenic plants with single copy and control NB1 was performed. The expression of $\operatorname{TaCKX} 2.4$ in the five transgenic plants was lower than that in the control (Fig. 4). The expression level of $\mathrm{TaCKX} 2.4$ was negatively correlated with grain numbers per spike, indicating that the reduced expression of TaCKX2.4 increased grain numbers in wheat (Fig. 6).

Table 1 Comparison of phenotypes between transgenic lines and the control NB1

\begin{tabular}{|c|c|c|c|c|c|c|}
\hline Line & $\begin{array}{l}\text { Spike length } \\
(\mathrm{cm})\end{array}$ & Kernel width (mm) & $\begin{array}{l}\text { Kernel length } \\
(\mathrm{mm})\end{array}$ & $\begin{array}{l}\text { Thousand-grain } \\
\text { weight }(\mathrm{g})\end{array}$ & $\begin{array}{l}\text { Grain numbers } \\
\text { per spike }\end{array}$ & $\begin{array}{l}\text { Increased grain numbers } \\
\text { per spike }(\%)\end{array}$ \\
\hline JW41-1B & 10.9 a & $3.40 a$ & $6.90 \mathrm{a}$ & $31.1 \mathrm{a}$ & $56.0 \mathrm{a}$ & - \\
\hline JW1-1A & $11.0 \mathrm{a}$ & $3.35 a$ & $6.75 a$ & $29.5 \mathrm{a}$ & $59.2 \mathrm{~b}$ & 6.5 \\
\hline JW39-3A & $11.6 \mathrm{a}$ & $3.40 \mathrm{a}$ & $7.00 \mathrm{a}$ & $30.6 \mathrm{a}$ & $62.6 \mathrm{c}$ & 12.6 \\
\hline JW5-1A & $10.7 \mathrm{a}$ & $3.45 \mathrm{a}$ & $6.75 \mathrm{a}$ & $29.1 \mathrm{a}$ & $58.8 \mathrm{~b}$ & 5.8 \\
\hline JW1-2B & $11.1 \mathrm{a}$ & $3.45 \mathrm{a}$ & $6.75 \mathrm{a}$ & $29.1 \mathrm{a}$ & $60.2 \mathrm{~b}$ & 8.3 \\
\hline NB1 & $10.8 \mathrm{a}$ & $3.40 \mathrm{a}$ & $7.00 \mathrm{a}$ & 30.9 a & $55.6 \mathrm{a}$ & - \\
\hline
\end{tabular}

Different lowercase letters following the values indicate significant differences $(P<0.05)$ 


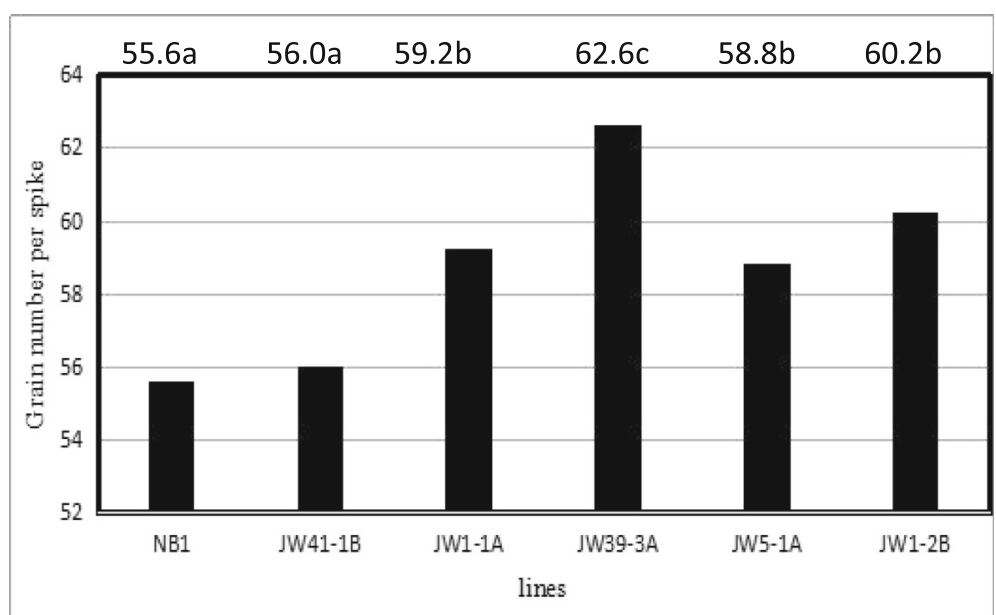

Fig. 5 Grain numbers per spike from main tiller in NB1 and five transgenic lines. Different lowercase letters following the values indicate significant differences $(P<0.05)$

\section{Discussion}

The aim of the current study was to specifically down regulate the expression of $\operatorname{TaCKX} 2.4$ using shRNA-mediated gene silencing to examine its influence on wheat yield-related traits. Here we showed that iRNA-TaCKX2.4 transgenic wheat lines expressed the shRNA efficiently and specifically reduced the expression of homologous TaCKX2.4 (Fig. 4), consistent with those of transgenic rice and barley plants that harbored hairpin (hp) RNA-expression constructs containing rice OsCKX2 sequences [21], and barley yellow dwarf virus-PAV sequences [26], and partial cDNA fragments of $H \nu C K X 1$ [17], resulting in blockage of the translation of target mRNAs into proteins. Our results showed that PiCKX2.4 was stably inherited in transgenic lines. The iRNA-TaCKX2.4 transgenic lines in this study contained one copy of the silencing genes in the genome
(Fig. 3), conferring an efficient reduction of TaCKX2.4 transcript in all lines except for JW41-1B (Fig. 4).

Because CKX is the only known enzyme responsible for irreversible degradation of cytokinins in plants, mutant or transgenic plants with low expressing levels of $C K X$ genes have been shown to possess a clear cytokinin-overproducing phenotype. Recent genetic transformation studies suggest that crop productivity can be enhanced by decreasing the expression of $C K X$ gene [21]. Decreased expression of OsCKX2 in transgenic rice by anti-sense also leads to increased grain numbers per panicle [15]. There were more capsules in transgenic CKX-suppression tobacco plants than in control [27].

In wheat, the relationship between the expression of $C K X$ gene and the number of reproductive organs has not been confirmed by a direct validation via gene

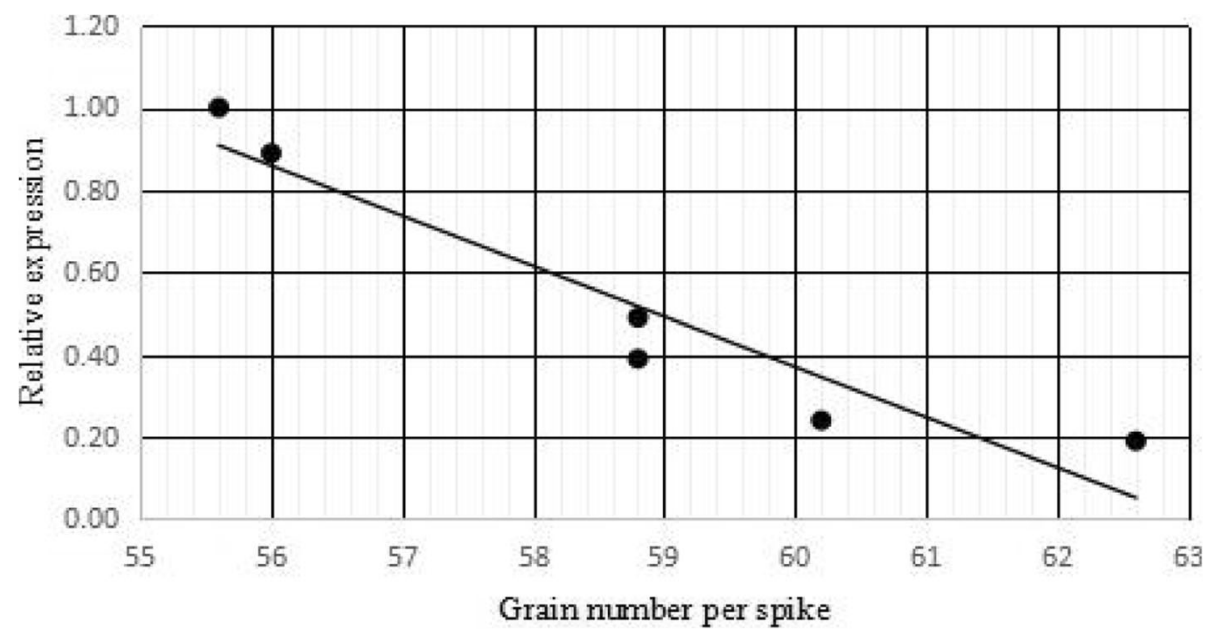

Fig. 6 The trendline for the relation between relative expression of TaCKX2 and grain numbers per spike from main tiller in NB1, JW41-1B, JW51 A, JW1-1A, JW1-2B and JW39-3A 
transformation before. Here we investigated the relationship between the expression level of TaCKX2.4 gene and the grain number per spike, spike length, thousand-grain weight, seed length and seed width in transgenic wheat plants with TaCKX2.4 RNA interference vector. The results showed a significantly negative correlation between the expression of TaCKX2.4 and grain numbers, consistent with those in rice [21] and Arabidopsis thaliana [13], but opposite to previous results obtained in wheat where the increasing of TaCKX2.1/TaCKX2.2 expression could lead to the increase of grain number per spike [18]. Decreased expression of the TaCKX1, TaCKX2 and TaCKX6 may lead to the accumulation of CK in NIL31 (TaGW2-6A allelic variants) [28]. The TaCKX2.4 RNA interference vector reduced the activity of the cytokinin oxidase in transgenic plants, which caused accumulation of cytokinin in inflorescence meristems and increased the number of reproductive organs, leading to increasing grain numbers per spike.

In wheat,five $T a C K X 2$ genes were reported, and they were located on the short arms of the group 3 chromosome $[18,22]$. TaCKX2.4 was mapped on chromosome $3 \mathrm{~A}, \mathrm{TaCKX} 2.5$ was mapped on chromosome 3B, and TaCKX2.1, TaCKX2.2 and TaCKX2.3 were mapped on chromosome 3D $[18,22]$. Alignment of the CDS and amino acid of TaCKX2.4 with TaCKX2.1, TaCKX2.2, TaCKX 2.3 and TaCKX2.5 showed sequence identity of $93 \%, 93 \%, 85 \%$ and $85 \%$, respectively, and $92 \%, 91 \%, 80 \%$ and $80 \%$, respectively. High sequence identity indicates that they have similar biological functions [18].

To the best of our knowledge, this is the first study to verify the function of $T a C K X 2.4$ in wheat, where an efficient suppression of TaCKX2.4 is successfully achieved by shRNAi.

\section{Conclusion}

This study constructed a plant expression RNAi vector pBIOS2043-TaCKX2.4 and obtained five transgenic wheat lines with single copies of transformed targeting gene using the infection of Agrobacterium tumefaciens strain EHA105. The positive transgenic plants had significantly lower expression of $\mathrm{TaCKX} 2.4$ and higher grain numbers per spike than the control NB1. It was shown that the reduced expression of TaCKX2.4 significantly increased grain numbers in wheat.

\footnotetext{
Abbreviations

AS: Acetosyringone; CK: Cytokinin; CKX: Cytokinin oxidases/dehydrogenases; GMO: Genetically modified organism; GN: Grain number per spike; qRTPCR: Quantitative real-time PCR; SL: Spike length; SPN: Spikelet number per spike; TGW: Thousand-grain weight
}

\section{Acknowledgements}

This work was supported by the Youth Foundation of Shandong Academy of Agricultural Sciences (2014QNZ02), National Natural Science Foundation of China (31401378, 31501312, 31701428 and 31601301), Science and Technology Development Plan of Shandong Province (2014GSF121001), Genetically
Modified Organisms Breeding Major Project (2016ZX08002003), Key Research and Development Plan of Shandong Province(2017GNC10113), Agricultural Science and Technology Innovation Project of Shandong Academy of Agricultural Sciences (CXGC2016C09), the Natural Science Foundation of Shandong Province (ZR2014CM006), the youth Talent Program of Shandong Academy of Agricultural Sciences and Youth of Foundation of Crop Research Institute of Shandong Academy of Agricultural Sciences.

\section{Funding}

This work was supported by the Youth Foundation of Shandong Academy of Agricultural Sciences (2014QNZ02), National Natural Science Foundation of China (31401378, 31501312, 31701428 and 31601301), Science and Technology Development Plan of Shandong Province (2014GSF121001), Genetically Modified Organisms Breeding Major Project (2016ZX08002003), Key Research and Development Plan of Shandong Province(2017GNC10113), Agricultural Science and Technology Innovation Project of Shandong Academy of Agricultural Sciences (CXGC2016C09), the Natural Science Foundation of Shandong Province (ZR2014CM006), the youth Talent Program of Shandong Academy of Agricultural Sciences and Youth of Foundation of Crop Research Institute of Shandong Academy of Agricultural Sciences.

\section{Availability of data and materials}

The authors declare that the data supporting the findings of this study are available within the article.

\section{Authors' contributions}

YL transformed the target gene and wrote the paper; GS did the southern blotting analysis; JG transformed the target gene; SZ constructed the vector; RZ analyzed the data; WL detected the transgenic plants; $\mathrm{MC}$ was responsible for plant cultivation and management; ML was in charge of the survey of agronomic traits; XX was revised the article; TR constructed the vector; GL conceived the study. All authors read and approved the final manuscript.

\section{Ethics approval and consent to participate}

No applicable.

\section{Consent for publication}

Not applicable.

\section{Competing interests}

The authors declare that they have no competing interests.

\section{Publisher's note}

Springer Nature remains neutral with regard to jurisdictional claims in published maps and institutional affiliations.

\section{Author details}

${ }^{1}$ Crop Research Institute, Shandong Academy of Agricultural Sciences; Key Laboratory of Wheat Biology and Genetic Improvement on North Yellow and Huai River Valley, Ministry of Agriculture, National Engineering Laboratory for Wheat and Maize, Jinan 250100, Shandong, China. ${ }^{2}$ Biogemma, Site de la Garenne, CS 90126, 63720 Chappes, France. ${ }^{3}$ Institute of Crop Sciences, National Wheat Improvement Center, Chinese Academy of Agricultural Sciences (CAAS), 12 Zhongguancun South Street, Beijing 100081, China.

Received: 7 June 2018 Accepted: 21 September 2018

Published online: 02 October 2018

References

1. Davies PJ. Physiology, biochemistry, and molecular biology: plant hormones. 2nd. ed. Dordrecht, Boston, London: Kluwer Academic publishers; 1995.

2. Mok DW, Mok MC. Cytokinin metabolism and action. Annu Rev Plant Physiol Mol Biol. 2001;52:89-118.

3. To JPC, Kieber JJ. Cytokinin signaling: two-components and more. Trends Plant Sci. 2008;13:285-92.

4. Yang JC, Peng SB, Visperas RM, Sanico AL, Zhu QS, Gu SL. Grain filling pattern and cytokinin contentin the grains and roots of rice plants. Plant Growth Regul. 2000;30:261-70.

5. Yang JC, Zhang JH, Wang ZQ, Zhu QS. Hormones in the grains in relation to sink strength and postanthesis development of spikelets in rice. Plant Growth Regul. 2003;41:185-95. 
6. Yang DQ, Li Y, Shi YH, Cui ZY, Luo YL, Zheng MJ, Chen J, Li YX, Wang ZL. Exogenous cytokinins increase grain yield of winter wheat cultivars by improving stay-green characteristics under heat stress. PLoS One. 2016;11(5): e0155437. https://doi.org/10.1371/journal.pone.0155437.

7. Chen JB, Liang Y, Hu XY, Wang XX, Tan FQ, Zhang HQ, Ren ZL, Luo PG Physiological characterization of 'stay-green' wheat cultivars during the grain filling stage under field growing conditions. Acta Physiol Plant. 2010;32:875-82.

8. Brestic M, Zivcak M, Hauptvogel P, Misheva S, Kocheva K, Yang XH, Li XN, Allakhverdiev $\mathrm{S}$. Wheat plant selection for high yields entailed improvement of leaf anatomical and biochemical traits including tolerance to nonoptimal temperature conditions. Photosynth Res. 2018;136(2):245-55.

9. Schmülling T, Werner T, Riefler M, Krupková E. Bartrina y Manns I. structure and function of cytokinin oxidase / dehydrogenase genes of maize, rice, Arabidopsis and other species. J Plant Res. 2003;1 16:241-52.

10. Galuszka P, Frébort I, Šebela M, Sauer P, Jacobsen S, Peé P. Cytokinin oxidase or dehydrogenase? Eur J Biochem. 2001;268:450-61.

11. Jones RJ, Schreiber BMN. Role and function of cytokinin oxidase in plants. J Plant Growth Regul. 1997;23:123-34.

12. Houba-Hérin N, Pethe C, d'Alayer J, Laloue M. Cytokinin oxidase from Zea mays: purification, cDNA cloning and expression in moss protoplasts. Plant J. 1999;17:615-26

13. Werner T, Motyka V, Laucou V, Smets R, Van H, Schmulling T. Cytokinindeficient transgenic Arabidopsis plants show multiple developmental alterations indicating opposite functions of cytokinins in the regulation of shoot and root meristem activity. Plant Cell. 2003;15:2532-50.

14. Yang SH, Yu H, Goh CJ. Characterisation of a cytokinin oxidase gene DSCKX in Dendrobium orchid. Plant Mol Biol. 2003;51:237-48.

15. Ashikari M, Sakakibara H, Lin S, Yamamoto T, Takashi T, Nishimura A, Angeles R, Qian Q, Kitano H, Matsuoka M. Cytokinin oxidase regulates rice grain production. Science. 2005;309:741-5.

16. Galuszka P, Frebortova J, Werner T. Cytokinin oxidase / dehydrogenase genes in barley and wheat: cloning and heterologous expression. Eur J Biochem. 2004;271:3990-4002.

17. Zalewski W, Galuszka P, Gasparis S, Orczyk W, Nadolska-Orczyk A. Silencing of the HvCKX1 gene decreases the cytokinin oxidase / dehydrogenase level in barley and leads to higher plant productivity. J Exp Bot. 2010;61:1839-51.

18. Zhang JP, Liu WH, Yang XM, Gao AN, Li XQ, Wu XY, Li LH. Isolation and characterization of two putative cytokinin oxidase genes related to grain number per spike phenotype in wheat. Mol Biol Rep. 2011;38:2337-47.

19. Zhang L, Zhao YL, Gao LF, Zhao GY, Zhou RH, Zhang BS, Jia JZ. TaCKX6-D1, the ortholog of rice OsCKX2, is associated with grain weight in hexaploid wheat. New Phytol. 2012;195:574-84.

20. Ma X, Feng DS, Wang HG, Li XF, Kong LR. Cloning and expression analysis of wheat cytokinin oxidase/dehydrogenase gene TaCKX3. Plant Mol Biol Rep. 2011;29:98-105

21. Yeh SY, Chen HW, Ng CY, Lin CY, Tseng TH, Li WH, Ku MSB. Downregulation of cytokinin oxidase 2 expression increases tiller number and improves rice yield. Rice. 2015;8:36.

22. Mameaux S, Cockram J, Thiel T, Steuernagel B, Stein N, Taudien S, Jack P Werner P, Gray JC, Greenland AJ, Powell W. Molecular, phylogenetic and comparative genomic analysis of the cytokinin oxidase/dehydrogenase gene family in the Poaceae. Plant Biotechnol J. 2012;10:67-82.

23. McElroy $D$, Blowers $A D$, Jenes $B$, Wu R. Construction of expression vectors based on the rice actin 1 (Act1) $5^{\prime}$ region for use in monocot transformation. Mol Gen Genet. 1991;231:150-60.

24. Risacher T, Craze M, Bowden S, Paul W, Barsby T. Highly efficient Agrobacterium-mediated transformation of wheat via in planta inoculation In: Jones HD, Shewry PR, editors. Methods in molecular biology, transgenic wheat, barley and oats, Vol478. Totowa, NJ: Humana; 2009. p. 115-24.

25. Ramya P, Chaubal A, Kullkarni K, Gupta L, Kadoo N, Dhaliwal HS, Chhuneja P. QTL mapping of 1000-kernel weight, kernel length, and kernel width in bread wheat ( Triticum aestivum L.). J Appl Genet. 2010;51:421-9.

26. Wang MB, Abbott DC, Waterhouse PM. A single copy of a virus-derived transgene encoding hairpin RNA gives immunity to barley yellow dwarf virus. Mol Plant Pathol. 2000;1:347-56.

27. Zeng QW, Qin S, S-q S, Zhang M, Y-h X, Luo M, Hou L, Pei Y. Molecular cloning and characterization of a cytokinin dehydrogenase gene from upland cotton (Gossypium hirsutum L.). Plant Mol Biol Rep. 2012;30:1-9.

28. Geng J, Li LQ, Lv Q, Zhao Y, Liu Y, Zhang L, Li XJ. TaGW2-6A allelic variation contributes to grain size possibly by regulating the expression of cytokinins and starch-related genes in wheat. Planta. 2017;246:1153-63.

Ready to submit your research? Choose BMC and benefit from:

- fast, convenient online submission

- thorough peer review by experienced researchers in your field

- rapid publication on acceptance

- support for research data, including large and complex data types

- gold Open Access which fosters wider collaboration and increased citations

- maximum visibility for your research: over $100 \mathrm{M}$ website views per year

At $\mathrm{BMC}$, research is always in progress.

Learn more biomedcentral.com/submissions 